\title{
The Realistic Problems of Basic Education Teachers' Professional Salary and Solutions
}

\author{
Dong Feng, Xue Wang*, and Xia Guo \\ Xi 'an international studies university school of education, $710000 \mathrm{Xi}$ 'an, China
}

\begin{abstract}
Good policy treatment is an important guarantee to improve the quality of primary and secondary school teachers. China's policies clearly put forward that it's necessary to continuously improve the status and treatment of teachers in basic education, so that teachers can truly become an enviable career. At present, the professional treatment situation of basic education teachers in China is not optimistic, which is far from the policy ideal. There are many problems, such as the lack of occupational attraction, the overall salary level is relatively low, and the implementation of subsidies and welfare policies is not in place.By further increasing the salary level of teachers, balancing the treatment of different groups of teachers, improving the implementation of subsidies and welfare policies, implementing the provincial overall treatment of basic education teachers, increasing the implementation of inspection of professional treatment of teachers and other measures to enhance the vocational attraction of basic education teachers,the high-quality development of China's basic education can be ensured.
\end{abstract}

\section{Introduction}

Education is the foundation of long-time plan. And teachers are the base of education plan. Primary and secondary school teachers are at the stage of basic education and have a foundational position in the overall development of students' body and mind. The admission, promotion, development, and exit guarantee mechanism of individual teachers can effectively stimulate teachers' vitality and dedication, enhance the faculty of basic education teachers, and promote more outstanding talents to be enthusiastic about teaching. Moreover, in remote rural areas, the construction of teachers is a strategic focus for the overall improvement of rural education quality, and it is also an important aspect of highlighting education equity. The quality of the teaching staff is closely related to the quality of education. [1] But in reality, the professional treatment of teachers in basic education in our country is not optimistic. Compared with the treatment of teachers in developed countries in the world, there is still a big gap compared with that of civil servants. Although the Teacher Law clearly stipulates that "the average salary of teachers should be no lower or higher than the average salary of national civil servants", what is the current status of the local government's implementation of the professional treatment of teachers?

* Corresponding author:xuewang197@163.com 
What is the teaching vitality and professional identity of front-line teachers and the professional attractiveness of basic education teachers? How to further improve the basic education teacher treatment guarantee system? Many problems need to be solved urgently.

\section{The Analysis Paradigm of Teachers' Professional Treatment}

When consulting related literature, it is found that Zhang Tianzhen [2], Fan Jingyi [3] and other scholars have roughly three parts in their understanding of the term "remuneration". One is the various wages and bonuses that the employer directly pays to the laborer, the second is the various goods and services provided by the unit to workers for free or below cost. This part of labor remuneration is called wages in kind, the third refers to the insurance premium paid directly to the government and the insurance department after the employer signs the labor contract with the worker.

According to the document "National Medium and Long-term Educational Reform and Development Plan (2010-2020)", the professional treatment of teachers should include the following four aspects: first, the material conditions of the teacher's work and life. It mainly refers to teaching equipment, accommodation conditions, etc. The second is teachers' wages. Generally speaking, it also refers to teachers' basic salary, performance bonus, various subsidies etc., mainly exist in the form of currency. Due to the complex classification of performance bonuses, the calculation rules are more cumbersome, and there are large differences between different regions and schools. This mainly refers to moral education performance, activity development performance, teaching achievement performance, and delayed service performance of some schools, etc. Various subsidies mainly include teacher-specific subsidies, such as class teacher subsidies, incentive subsidies (for publishing papers or participating in competitions), accommodation subsidies, communication subsidies, lunch subsidies, etc. The third is the social security system, mainly refers to medical pension policies and preferential treatment policies for teachers' children. Various types of social insurance mainly refer to five social insurances and one housing fund, namely medical care, pension, unemployment, work-related injury, maternity insurance, and housing provident fund. The fourth is welfare. It mainly refers to various items provided by employers to teachers for free, such as shopping cards, gift vouchers, free working meals provided, items distributed on holidays, etc.

Consider the impact of statistics on economics and education on the professional treatment of teachers, and use qualitative research methods based on the principle of convenience sampling. 5 randomly selected first-line teachers from primary and middle schools in central and suburban areas of Chengdu as interview subjects. The interview time is about 40 minutes per person

\section{The problems of basic education teachers' professional treatment}

At the National Education Conference held on September 10, 2018, General Secretary Xi Jinping clearly instructed that the balance of "education investment" should be tilted more towards teachers. [4] However, there are still some practical problems that need to be solved urgently in the professional treatment of basic education teachers in China. 


\subsection{Insufficient occupational attractiveness of basic education teacher salaries}

In 2018, the International Survey of Teacher Teaching published by the Organization for Economic Cooperation and Development (OECD) aims to provide time-sensitive and comparable international data for national policy making, referred to as TALIS. This data shows that the satisfaction of teachers' professional status in Shanghai in my country ranks third overall, and the high satisfaction of teachers is very significant, which is generally at a higher level in the world. [5] However, in contrast to professional status satisfaction, Shanghai teachers' satisfaction with salaries and benefits is not obvious, slightly lower than the world average, ranking 29th among 47 countries. The guarantee for basic education teachers' treatment in the compulsory education stage should follow this condition. [3] The data indicates that the professional attractiveness of basic education teachers mainly depends on the maintenance of professional status in the context of China, and the role of salary needs to be strengthened urgently.

\subsection{Obvious differences in salary groups for basic education teachers}

There is a big gap in the salary of teachers in different regions of the country. Some scholars compared the average salary of basic education teachers in various provinces in my country in 2011, and compared it with the per capital GDP of that year, confirming this conclusion. [6] The salaries of teachers in the eastern and western regions are relatively high, and the wages in the central region are relatively low, showing a recession. Although the state has continuously invested in rural education in western China over the years, the income of basic education teachers has increased significantly. [7] However, the eastern region has a developed economy and strong economic strength. The income of most basic education teachers in the eastern region remains significant, and the income of primary and secondary education teachers in the central region is significantly lower than that in the western region. According to the data in the "China Labor Statistics Yearbook", the salary level of teachers in developed areas is significantly higher than that in underdeveloped areas, and the annual average salary of primary school teachers in different areas varies greatly. The teachers interviewed agreed that the salary income of teachers in first-tier cities such as Shanghai and Beijing is very considerable, and the polarization of basic education teacher salaries between different regions is quite obvious.

The salary and welfare of teachers are uneven among schools. The difference between urban and rural areas in educational resources cannot be ignored. In addition to the differences between urban and rural schools, the same is true for key schools in cities and ordinary schools. Interviewed teacher B mentioned that in the same school, there is also an injustice between the treatment of teachers in the establishment and the teachers of the appointment system. Take traditional public schools and new system schools as examples. In the new system schools, although the monthly income is more than that of traditional public elementary schools, the working hours and work intensity are infinitely expanded. In fact, the latter's basic salary and post-class delay Services, holiday benefits, bonuses are not as high as the former teachers.

\subsection{Subsidies and welfare policies are not in place}

A scholar's survey of more than 160 primary and secondary schools in 6 provinces in the central and western regions shows that the amount of subsidy for basic education teachers is very different from the incentive allowance (year-end performance appraisal award) enjoyed by local civil servants. The subsidy for basic education teachers is obvious. In a 
disadvantaged position, the daily work of basic education teachers is cumbersome and complicated, and they often need to complete tasks other than the prescribed tasks. Therefore, setting up a series of teacher allowances, such as teaching age allowance, class teacher allowance, etc., is the labor consumption and expenditure paid by basic education teachers under special working conditions. Teachers pay more compensation for their labor, but the implementation is not in place. [6] A large survey conducted by "China Education News" found that only $6 \%$ of teachers have enjoyed travel benefits, $8 \%$ of teachers have enjoyed academic leave benefits, $5 \%$ of teachers have enjoyed house purchase benefits, and about 36\% of teachers have enjoyed medical insurance benefits. [8] Combined with the results of related scholars' research and interviews, teachers' welfare benefits are generally low. Interviewed teacher B said that most of the items presented by the unit are cheap in kind, such as water cups and silk scarves. The common feature is that the purchase price is high and the actual use is small. Teachers also mentioned that they have to pay monthly meals, the cafeteria is not free, and the quality of the meals provided is average, reflecting the inadequacy of the teachers' living security.

\section{Countermeasures to improve the guarantee of professional treatment of teachers in basic education}

In China, that the basic education teachers' salary is not high is a long and even a long history of the problem. It appears to be an educational problem, but in essence it is a social, institutional, economic and cultural problem. Because the external relationship of education directly affects the internal relationship of education, it does not mean that the treatment of teachers cannot be solved.

\subsection{Increase government investment in basic education teachers' treatment}

The government should increase the investment in the treatment of teachers in basic education. Come around China in the 1980s "decision on reform of the education system of the central committee of the communist party of China" promulgated, teachers' salaries in China will gradually implement "local classification" management system, financial rights issued by the local government, township, the county government as a whole, it is easy to lead to the local government appropriation of teachers' salaries, teachers unpaid wages events frequently occur. [9] Throughout the world of the cost of compulsory education management system, with South Korea and Japan as an example, its compulsory education teachers' salaries in full by the central government or a high level of government as a whole, while China's current basic education teachers' pay is still at the county level as a whole is given priority to, and is responsible for township government, due to its financial strength is weak, so the implementation of basic education teachers treatment at the county level as a whole must step up efforts to promote. Provincial governments can pay teachers' wages across the province in accordance with national uniform wage standards or remuneration rules, and use special funds to directly transfer them to teachers' accounts. On the one hand, it is beneficial to prevent lower-level governments from embezzling. On the other hand, it is beneficial to improve efficiency, simplify procedures, maintain a relatively balanced salary level in the province, and promote the high-quality development of teachers. 


\subsection{Balance the wage difference between different groups, pay attention to the treatment of teachers and implement the supervision system}

First of all, the minimum wage should be set in the regional differences of teachers' pay. China has a large span of regions and different levels of economic development, resulting in obvious differences in teachers' salaries. In order to alleviate the polarization of basic education teachers' salary in different regions, a minimum wage standard should be set among the regional differences of teachers' salary. The central government should formulate macro policies on the treatment of teachers, ensure adequate educational funds and exercise supervision and management by local governments. Central governments and education departments also need to combine local education administrative departments, in accordance with the provisions of the same standards for teachers' salaries, will be the teacher of "shall not be less than or higher than the local civil servant wage" as a measure of a ruler, self-inspection, effective supervision, make the rational and orderly flow of basic education teachers, reducing the cost of good teachers.

Secondly, increase the treatment of teachers to implement the supervision system. The education steering committee office of the State Council issued the "deployment schedule implementation compulsory education teachers' wages to supervise" notice, compulsory education teachers' wage income in 2020 to carry out the situation to supervise to make specific arrangements, around the end of 2020 to implement compulsory education teachers' income level is not lower than the local average wage civil servants the overall objective of average wage income level, mainly studies around the nearly three years to promote overall goal to carry out the situation, relevant departments to establish long-term mechanism and guarantee compulsory education stage teacher wages as the civil service pay for flexible adjustment mechanism. Each provincial government should set up a special inspection team to conduct inquiries and interviews with local governments, and earnestly understand the implementation of policies through diversified methods such as unannounced visits and public feedback, and must not be formalized. It is also necessary to focus on the problem, realize the joint work organization of the three-level government of provinces, cities and counties, strengthen government responsibilities with high standards, clarify the reward and punishment system, stimulate the enthusiasm of all governments for self-examination, break their fluke psychology, achieve real implementation, and realize basic education good guarantee for teachers' professional treatment.

\subsection{Improve the implementation of subsidies and welfare policies, fully consider the particularity of teachers' work}

In addition to the basic salary, all kinds of subsidies for basic education teachers also occupy the majority of the proportion. The following mainly provide corresponding suggestions for teachers' teaching length subsidy, class teachers' subsidy, transportation subsidy and other aspects. In 1985, the wage system reform group of the State Council and the former Ministry of Labor and Personnel jointly issued the "Several Provisions on the Teacher's Teaching Age Allowance". However, this policy is difficult to adapt to the current level of economic development, taking Henan Province as an example, from July 1, 2019, the province's teachers' length of teaching allowance is adjusted to 10 yuan per month for each year of teaching, breaking the shackle of 34 years of teaching allowance. Therefore, the increase of teachers' teaching age subsidies should be spread to all regions of the country. [10] Under the background of comprehensively improving the quality of compulsory education, it is urgent to establish a transportation subsidy system to improve the status and treatment of teachers in basic education. The rise of transportation costs caused by economic and social development has become a basic problem affecting the 
professional treatment of teachers in basic education. Firstly, teachers' social status does not match their actual income level. Compared with other industries, the absence of transportation subsidy in the salary subsidy of teachers in basic education in China cannot be equated with the treatment of civil servants, and the status and treatment of teachers as professionals cannot match. Secondly, the actual cost of transportation for elementary education teachers lacks social attention. With the deepening of the reform of the education system, "inter-school communication", "shift system" and "school system" are becoming more and more common and frequent, and the proportion of official traffic volume and its expenditure in consumer expenditure is increasing. However, this practical problem has not been given due attention and institutional response.

\section{Conclusions}

To sum up, with the introduction of a series of documents and policies, the professional treatment of teachers in basic education in China has been significantly improved in recent years. However, due to the lagging implementation of policies and other reasons, there are still practical problems to be solved in the professional treatment of teachers in basic education in China. This research discusses the teachers' work of professional treatment in addition to the already defined and the material conditions of life, teachers' salaries, social security system and the welfare of the four basic structure. Compared with other industries it should also include teachers' self-happiness. Teachers' psychological balance between different areas is not easy to quantify and observed, so the research still has a very broad space for discussion.

This work is supported by the Xi'an 2021 Social Science Planning Fund Project "Research on Governmental Supervision and Support for Inclusive Private Kindergartens in Xi'an" (project number: JY167).

\section{References}

1. Y.Y.Qin, Educational Development Research, The construction of teachers is the strategic focus of the overall improvement of rural education quality, 35 (2015)

2. T.Z.Zhang, A Study on the Treatment of Primary School Teachers in Tianjin, (2018)

3. J.Y.Fan, A Study on the Relationship between Teachers' Labor Remuneration and Teachers' Professional Attraction, (2013)

4. Q.Liu, General Secretary Xi Jinping's important speech at the National Education Conference, https://max.book118.com/html/2020/0722/6233153103002222.shtm. Sep.2018, (2018)

5. W.T.Zeng, Educational Science Forum, Research on teachers' professional status, salary and willingness to teach from the perspective of international comparisonBased on TALIS2018 survey data, 10(514), 5-9, (2020)

6. Y.X.Zhu, Chinese Journal of Education, Effectively Improve Status and Salary to Strengthen Teachers' Professional Attraction, 04, (2018)

7. Y.L.Liu, H.H.T.Zhou, Educational Academic Monthly Journal,The internal logic, practical value and basic design of the subsidy system for teachers in elementary and middle schools, 07, 52-57, (2020)

8. F.Y.Hao, China Agricultural Education, An Analysis of the Salary Level of Teachers in Primary and Middle Schools in my country(1998 2011), 03, 83-87, (2014) 
9. W.D.Fu, Journal of Hebei Normal University (Educational Science), Unfairness and inadequacy of salary treatment of county compulsory education teachers: Difficult problems and solutions, 21(04), 5-12, (2019)

10. X.R.Fen, M.X.Liu, Peking University Education Review, Compulsory education teachers' online demands for wages and benefits: a research based on the big data of the national online political platform, 18(03):145-171+191, (2019) 